\title{
Organisational Identity Threats and Aspirations in Reputation Management
}

Heike Döring, James Downe, Hadar Elraz and Steve Martin

Cardiff Business School, Aberconway Building, Colum Drive, Cardiff CF10 3EU, UK

DoeringH@cardiff.ac.uk, Corresponding author

James Downe, Wales Centre for Public Policy 10-12 Museum Place, Cardiff CF10 3BG, UK

DowneJ@cardiff.ac.uk

Hadar Elraz - Lancaster University School of Management Bailrigg, Lancaster LA1 4YW, UK

h.elraz@lancaster.ac.uk

Steve Martin, Wales Centre for Public Policy, 10-12 Museum Place, Cardiff CF10 3BG, UK steve.martin@wcpp.org.uk

\begin{abstract}
Reputational threats are key to understanding public services' behaviour. Previous research has viewed external performance assessments as an unwelcome imposition on public managers and a threat to organizational identity. Analysing the adoption of a self-imposed process of peer-led assessment by public managers in UK local government we show how the absence of performance assessment was seen as a reputational threat. Engaging proactively with the new voluntary assessments becomes an essential tool for active reputation management. We find that reputation does not only shape the responses to external performance assessment but the external performance assessment itself
\end{abstract}

Keywords: Organisational identity, performance assessment, public services, reputation, organisational branding 


\section{Organisational Identity Threats and Aspirations in Reputation Management}

\section{Introduction}

The UK has been at the forefront of the "audit explosion" (Power, 2007), deploying external performance assessments to highlight organisational performance and drive public service reforms. The resulting ratings and 'league tables' sparked questions about "who we are" as public sector organisations (Rondeaux 2006, 2014; Wæraas 2010; Tuck 2015; Skålen 2004, Palma, Cunha and Lopes 2010; Ratner 2012). Previously, external performance assessments discussed in Higher Education and the police (Elsbach and Kramer 1996; Seeber et al. 2015; Jacobs et al.2008), for example, have been seen as threats to organisations' perceptions of themselves (Martins 2005). More recently, however, we have witnessed a 'reputational turn' (Busuioc and Lodge 2016, 2017; Wæraas and Maor 2015) in the literature highlighting how reputational considerations are central to understanding public organisations' engagement with external performance assessments (Carpenter and Krause 2012; Wæraas, Bjørnå and Moldenæs 2015).

In this paper, we examine the reciprocal relationship between external performance assessments and public organisations' reputation. External performance assessments, we argue, are not always perceived as a threat to organisations' views of themselves and their reputations but can be turned into opportunities to present identity aspirations (Kodeih and Greenwood 2014). The site of our investigation is English local government where obligatory and external performance assessments imposed by national government have been replaced with a voluntary, peer-led process called Corporate Peer Challenge (CPC) created by the local government sector. The question we investigate is what is the relationship between external performance assessments and reputation management. Carpenter and Krause (2012, 26) have focused on the nature of reputation as an outcome of a process by suggesting "that understanding how organizational reputations are formed and subsequently cultivated is 
fundamental to understanding the role of public administration in a democracy." At the same time, reputation has been acknowledged as a driver behind public organisations' behaviour (Busuioc and Lodge 2016, 2017). We provide empirical support and add theoretical insights to these debates.

Our analysis of managers' accounts of their engagement with assessments shows how, in a context in which organisational performance has become a central and distinctive characteristic of organizational identity, the absence of performance assessment serves as a reputational threat. Voluntary and proactive engagement with new forms of performance assessment is both a result of current organizational identity (cf. Gilad 2015) but also the opportunity for active reputation management. Thus, we contribute to the literature on organisational identity in public services in the context of institutional complexity (Meyer and Hammerschmid 2006; Rondeaux 2006, 2014; Skålen 2004; Tuck 2015; Wæraas 2010). We highlight synergies with the adjacent literature on reputation management in the context of public administration. Our analysis of external performance assessments links with the recent trends of "critical and/or evaluative deconstructions of NPM" (Osborne 2017, 109), showing that the relationship between organisational identity, reputational threats and organisational responses needs to be considered as dynamic and reciprocal process.

The first section of the paper provides an overview of the concepts of organisational identity and reputation which are central to our analysis. Next, we describe the site of our research, and outline our data sources and methods. We then present our findings before concluding with a discussion of the paper's contribution to theory and practice.

\section{Organisational identity and reputation in public management}


As part of an attempt to evaluate the impact of NPM reforms, there has been sustained interest in their relationship with identity. So far, the focus has been on reacting to NPM as a threat to public service identities and the strategic and flexible construction of complex and hybrid identities by individuals in organisations (Rondeaux 2006). There is, however, also a growing literature on the identity of public sector organisations. The seminal definition by Albert and Whetten (1985) identified three criteria of organisational identity: features had to be recognized as central, enduring and distinctive. They must represent the "essence" of the organisation, show a degree of continuity over time and make the organisation sufficiently distinct from comparable others (ibid, 265). These features, however, are not immutable. Organisational identity is created and continually constructed through the ongoing "interchange between internal and external definitions of the organisation offered by all organisational stakeholders" (Hatch and Schulz, 2002, 1004).

Initially, the literature on organisational identity and public service organisations was narrow in its preoccupation with organisations' identity as public or private sector (Albert and Whetten 1985). Palma et al (2010), for instance, chart the changing narratives of organisational identity of a public sector organisation following privatization. Similarly, Tuck (2015) discusses the tensions arising from the business versus public service juxtaposition for external stakeholders of public service organisations. Recent contributions have highlighted two insights relevant to our analysis. First, Gilad (2015) takes up previous discussions of the impact of organisational identity on organisations' actions (Dutton and Dukerich 1991, Randel, Jaussi and Standifird 2009) and details how external pressures and organisational identities interact to shape agencies' allocation of attention to tasks. Organisational identities condition agencies' response to public and political demands (Gilad 2015, 595). At the same time, persistent external demands may change organisations' view of themselves and their purpose and thus have an impact on the focus of organisational activity. Second, Bankins 
and Waterhouse (2019) explicitly make the link between organisational identity and reputation in their examination of the impact of organisational identity on public organisations' position in the labour market. They identify construed external image, individuals' levels of public service motivation and their alignment with NPM reforms as important factors for organizational identity and, ultimately, reputation. Similar to recent contributions to the literature on reputation and public organisations, however, their discussion remains at the theoretical level.

The link between research on organisational identity and reputation management is apt, even necessary if, so far, neglected (Carpenter and Krause 2012, Wæraas, Bjørnå and Moldenæs 2015). Carpenter and Krause (2012) establish that reputation needs to be seen as encompassing four dimensions impacting on both behaviour of members of the organisation and its observers. They identify: moral reputation, procedural reputation, technical reputation and, most important for us, performative reputation. Moral reputation refers to the public agency's compassion, flexibility and honesty in its dealing with its constituents. The agency's attitudes to following rules and norms are evaluated in the procedural dimension. Questions of skill and capacity are linked to technical reputation. Finally, concerns about the public organisation's capacity to "do its job" in a competent and efficient manner are evaluated in its performative reputation (Carpenter and Krause 2012, 27). Busuioc and Lodge (2017, 93) link organisational identity, defined as 'core competency' to these four areas of reputational investment. Here we have an explicit acknowledgement of performance as key to organizational reputation. Not only do these authors make performance visible in reputations, they also argue that "much of the richness of administrative behaviour will be lost" (Carpenter and Krause 2012, 31) if attention is only paid to reputation as a binary outcome of public agency's actions, as something that organisations have or do not have. Instead focus should be directed to examining the dimensions identified above. Despite the centrality of 
performance assessment to NPM (Radin 2006), performance as a central, enduring and distinctive element of organisational identity has not been studied extensively. In this paper, we therefore move performance and performative reputation centre stage.

Wæraas and Maor (2015) identify two research traditions in the field of bureaucratic and administrative reputation: a political science approach and an organisational approach. The political science perspective focuses on executive agencies, their striving for uniqueness in the political field and their strategic responses to reputational threats. A recurring argument is that organisations' perceptions of themselves shape the way organisations respond to external pressures and the need for change. In the organisational tradition, a range of public sector organisations have been examined, including public health care organisations (Wæraas and Sataøen 2015; Sataøen and Wæraas 2015) and local government (Wæraas Bjørnå and Moldenæs 2015; Houlberg Salomonsen and Nielsen 2015). The focus here is on the "symbolic management of reputation" (Wæraas and Maor 2015, 6) in the context of NPM reforms. This tradition explicitly highlights the problem of multiple stakeholders inside and outside the organisation. Few studies, however, pay attention to both groups and the careful balancing act between politics and administrative interests (Houlberg Salomonsen and Nielsen 2015).

This arbitration between different interests is often played out in organisations' engagement with external performance assessment. Public sector organisations are performing for multiple audiences including central government, key partners, and the general public. As a result, performance in the public sector is multi-dimensional, dynamic and frequently contested (Boyne, 2003). Public service organisations are typically evaluated according to multiple criteria including effectiveness in meeting organisational goals; efficiency in deploying resources; performance in comparison to other service providers; 
equality of access to services; robustness of their internal processes; and the transparency and accountability of decision-making processes.

Despite this complexity, studies have shown that public actors engage proactively with external assessments and reputational concerns are at the root of this. "[G]iving account of oneself, according to set criteria, serves as a way of justifying one's existence and can therefore become central to an organization's and individual's identity" (Busuioc and Lodge, 2016, 249). We build on this by focusing on corporate performance as central to public organisations' identity. In addition, Busuioc and Lodge (2016) posit that organisations' involvement in voluntary forms of assessment allows them a level of control over the content, audience and mechanisms of assessment which, in turn, yields reputational benefits. Internal tensions also add complexity to reputation management (Busuioc and Lodge 2017) but have so far been under-represented in research (Houlberg Salomonsen and Nielsen 2015). Reputational concerns, however, not only shape public organisations' relationship with external assessment. External assessors themselves face reputational dilemmas (Busuioc and Lodge 2017). The reputational investment of both parties ultimately shapes the character of the relationship between those presenting themselves and their performance and the assessors. In this article, we therefore follow an approach that focuses on identity dynamics in which public managers take an active role in mediating between external and internal stakeholders (cf. Gioia, Price, Hamilton and Thomas 2010).

We identify a number of recurring themes in the literature on organisational identity and reputation management which guide our analysis. Reputational threats are central to an understanding of organisations' behaviour (Carpenter 2010; Maor 2015). There is, however, an underlying assumption that these threats are recognized as such. Such events are overwhelmingly discussed as discreet events rather than recurring processes (despite the regular nature of rankings, for instance). In addition, research focuses on organisational 
responses and therefore the impact of these threats. Opportunities for organisations to respond to these threats are seen as unproblematic although Busuioc and Lodge $(2017,92)$ acknowledge that an 'actor's account cannot succeed without being 'heard' or received by the audience." This highlights the importance of understanding the relationship between organisations and their audiences. At the same time, there is a fundamental tension in the literature on reputation describing it as both filtering mechanism and outcome of organisational behaviour. This tension, however, remains largely unacknowledged. So far, the interdependent nature of organisational identity threats and responses, and therefore the impact of organisations on organisational identity threats, has been under-researched. The case we present provides insight into the issues of the nature of threats, the role for audiences and the dynamic relationship between organisational identity and reputation management through external performance assessments. We show how public service organisations engage with recurring external performance assessments and changes to assessments which undermines a straightforward organisational identity threat-organisational response relationship.

\section{Research site, methods and analysis}

The UK was an early adopter of value-for-money audits, external inspection, and the use of performance league tables and 'star ratings' to rate public service organisations. They have played a pivotal role in shaping both internal and external perceptions of public service organisations and making or breaking the careers of the head teachers, chief constables, and chief executives who lead them. In the early 2000s, the performance of local government and fire and rescue services was evaluated by external inspectors using a 'Best Value' performance management framework which sought to ensure that organisations adopted 
practices to ensure continuous improvement in services. From 2002 to 2008, the overall performance of local governments was scored using 'Comprehensive Performance Assessments' (CPAs) which marked them on a five-point scale from 'poor' to 'excellent'. CPAs were briefly replaced by 'Comprehensive Area Assessments' (CAAs) which extended the CPA methodology to health, fire and police services and judged the effectiveness with which these organisations and local governments worked together to serve the needs of their local populations. However, in 2010, the UK Government abolished CAAs and announced its intention to wind up the Audit Commission which had been responsible for the design and implementation of external performance assessment regimes and national performance indicators (Tonkiss and Skelcher, 2015).

In place of these 'top down' performance indicators and external inspections of local government, the Local Government Association (LGA) (the representative body of local governments in England) introduced a new approach based on peer-led performance reviews, known as Corporate Peer Challenge. In this process, local governments were able to request a visit by a small group of senior managers and politicians (typically four people on a team) from other councils to assess their overall performance and advise on areas for improvement. The process involves documentary analysis and visits by peers for up to a week, utilizing mainly interviews and focus group discussions with key stakeholders. The CPC process is 'designed to be forward looking, facilitative and problem solving' (LGA, 2016: 10). Organisations are able to utilise the feedback from peers as a way of improving their performance. CPC is voluntary but more than half of English local governments engaged with the process in its first three years of operation. In 2016/17 and 2017/18 a fifth of the sector engaged in peer challenges with some organisations participating in their second peer challenge since the establishment of the programme (LGA website). Whilst there are core components to every $\mathrm{CPC}$, assessments are tailored to the needs of the organisation which 
can ask for particular services or issues to be looked at (such as how to respond to austerity or ways to improve economic regeneration).

Unlike CPA and CAA, CPC is neither used to report upwards to central government or compile performance league tables nor is it aimed at the public as a key audience. Instead, assessors provide a verbal briefing and written report about the organisation's strengths and weaknesses with recommendations about how to address the latter. Publication of this report is at the discretion of each local government, although nearly all organisations do so. While local governments therefore no longer need to submit themselves to external scrutiny of their overall performance, a large number of local governments have opted into this voluntary programme. This points to a continuing appetite on the part of senior public managers for external assessment. This flies in the face of traditional accounts of local resistance to performance regimes of this kind (Ashworth, Boyne and Walker 2002) and presents interesting empirical insights to support and extend recent theoretical discussions of the relationship between accountability-seeking behaviour and reputation.

Our findings are based on an empirical analysis of data from interviews with 81 senior public managers (Chief Executives, Assistant Chief Executives and Heads of Policy and Performance, see table 1 below) and politicians (Council Leaders and Cabinet Members with responsibility for corporate performance). We also spoke to a small group of council officers and middle managers outside of senior management who were closely involved with the delivery of the Corporate Peer Challenge. Interviewees were drawn from 21 English local governments that were selected according to a range of criteria including region, type of organisation (i.e. district, county or unitary council ${ }^{\mathrm{i}}$ ) and prior experience of inspection (including organisations that had performed well in CPA and CAA and those whose performance had been heavily criticized). 
We recognize that our informants represent a particular vantage point within their organisations and that there are likely to be multiple perspectives of organisational identity in any organisation, which poses a significant challenge for reputational strategies (Houlberg Salomonsen and Nielsen 2015). Previous research into reputation management in local government emphasised how reputational strategies predominantly are an expression of senior management's goals and aspirations for the organisation (Bjørnå 2015). The specific programme of CPC is a corporate performance assessment, and it is primarily senior managers and politicians who initiated, managed and participated in the process (cf. Wæraas et al. 2015). They were, therefore, in a privileged position in terms of making sense of and giving sense to the practice. The LGA describes CPC explicitly as a programme "by the sector for the sector" (LGA 2016: 3) with very limited attention paid to the public. In addition, in contrast to previous assessment regimes, CPC did not reach far 'down' into councils. Service managers and frontline staff were not involved in the assessment and therefore would not be able to shed light on motivations for participation or uses of CPC. As a result, we focused our interview sample within the senior management team and leading politicians of participating organisations.

\section{TABLE 1 INTERVIEWEES ABOUT HERE}

Interviews took place in two phases of data collection between 2012 and 2014 as part of a wider, exploratory project on the organisational impact of sector-led improvement programmes. Interviews were semi-structured using a topic guide that focused on participants' experiences and perceptions of CPC, their motivation for engaging with it, the assessors' findings, and how they impacted on the organisation. Interviews were recorded and transcribed. 
In the extant literature, there are varying approaches to analysing accounts of organisational identity. One approach pays attention on how organisational identity provides both internal and external stakeholders with a sense of how an organisation might act and how it might be perceived (Gioia and Hamilton 2016). Here, organisational identity has a sensegiving function (Ravasi and Schultz 2006) and organisational identity threats can therefore also be considered sensegiving events. Another perspective focuses on how members of organisations individually and collectively come to understand and construct their organisation's central, enduring and distinctive features (Rondeaux 2006), also in response to organisational identity threats. Therefore, the literature in this tradition focuses on the sensemaking properties of organisational identity. The third approach highlights the impact of institutional forces on organisational identities. However, Gioia and Hamilton (2016) identify a lack of studies following an approach which provides a synthesis of the social actor and social constructionist perspectives given their complementary status (Ravasi and Schultz 2006). In this paper, we address this gap: by discussing the strategic use of peerled performance assessments by managers we acknowledge its sensegiving powers; by examining public managers' responses to it we highlight its sensemaking dimension. This also enables us to apply a multiple case study approach to provide an insight into field-level phenomena and thus link macro, meso and micro-level developments in public management.

The data were analyzed through iterative coding using Nvivo to examine the relationship between organisational identity and external threats (Ravasi and Canato, 2013). In the first instance, all 'identity-related incidents' (Ravasi and Schultz, 2006) were identified. This yielded 329 references covering an average of $22 \%$ of the recorded texts. For the second round of focused coding, a coding framework was developed by comparing and merging existing models of organisational responses to external organisational identity threats. We included the coding frameworks and models developed by Elsbach and Kramer 
(1996) and Kodeih and Greenwood (2014) discussing different mechanisms of evaluating organisational performance. In addition, Ravasi and Schultz's (2006) model of organisational responses to changes in the external environment of organisations was also consulted. All of these articles deal with threats to organisational identity and reputation, sensemaking and sensegiving. In particular, they focus on the interplay between external and internal stakeholders in identity dynamics. Table 2 below provides a summary of the themes from the literature which were used in building the coding framework.

\section{TABLE 2: CODING FRAMEWORK ABOUT HERE}

In a third round of coding, we identified gaps in this existing coding framework and introduced themes drawn from the public sector reputation literature, focusing on threats, audiences and dynamics. Although the themes are presented as analytically separate units, they are inter-related and were developed in relation to one another and in a way that highlight commonalities across the data set and beyond the boundaries of individual organisations. This paper uses a selection of quotations from interviews to exemplify these.

\section{Results}

Our analysis lends empirical support to recent theoretical suggestions of the need to move beyond a principal-agent understanding of external performance assessments (Busuioc and Lodge 2016, 2017, Karsten 2015). Contrary to much of the existing literature that presents external assessment of public services as a threat to organisational identities and reputations, and one that is liable to meet with local resistance, public managers saw considerable value in the external assessments provided by CPC. This can be understood by paying careful 
attention to the way in which reputational threat is constructed, multiple audiences are addressed through performance assessment and thus tensions between seeking legitimacy and reputation building as a competent organisation are carefully balanced (cf. Wæraas and Byrkjeflot 2012, Sataøen and Wæraas 2015). We find that organisational identity not only shapes the responses to external performance assessment but also perceptions of the external performance assessment itself.

\section{$\underline{\text { Recognizing Threats to Organisational Identity and Reputation }}$}

In line with the existing literature, interviewees reported differing sources for potential organisational identity threats. A number of interviewees cited internal changes (changing management teams or political leadership, change in organisational structure). Another group of interviewees admitted that they experienced changes in the external environment for public service organisations, such as financial constraints and the need to transform approaches to the delivery of services, as threats to their organisations and in particular as threats to performative reputation. These included new practices of performance assessment and new definitions of performance.

Senior managers were seeking to come to terms with the prospect of a prolonged period of austerity associated with the UK Government's deficit reduction strategy. Since 2010/2011 local government in England has faced unprecedented real terms cuts in the funding which it receives from central government. In order to survive in this new, much harsher financial climate, most councils had to initiate far-reaching efficiency and service transformation programmes which were taking them into unchartered waters. Senior managers were keen to hear from peers about ways in which they might protect frontline services from the worst 
effects of budget reductions and they sought reassurance that their plans would achieve the required savings. For example, one interviewee reported:

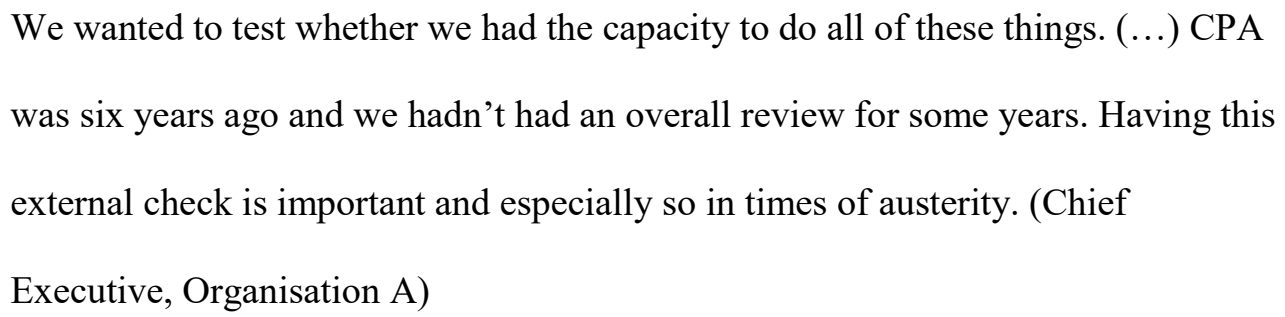

As this extract demonstrates, changes in the external, mainly financial, environment for public service organisations were not seen in isolation. Heightened threats to reputation for local government such as austerity and news stories of failing organisations contributed to increased interest in reputation management strategies. At the same time, the general sense of the need to address organisational practices was less significant than the sense of loss following the "bonfire of the inspectorates" (Middle Manager, Organisation B) i.e. the abolition of the Audit Commission and its inspection frameworks.

Interviewees across the organisations, but particularly those respondents who saw a discrepancy between the last mandatory external performance assessment (in the form of $\mathrm{CPA}$ and $\mathrm{CAA}$ ) and resulting reputation, and their claims in terms of organisational identity, lamented the abolition of external performance assessments.

\footnotetext{
At the time of the last CAA, at the end of the last government, [our organisation] was in a quite transitional state. [...] Consequently we got a very poor CAA rating. And having got that poor CAA rating, we were kind of looking forward to the following CAA where we would bear the fruit of our changes and of course, government changed and CAA was abolished. So we never really had a chance to officially sort of redress the balance from the poor CAA score. (Corporate Director, Organisation C)
}

This interviewee details how a lack of opportunity to present organisational responses to previous assessments created a sense of distress and provided a reason for them volunteering 
for CPC. Similarly, organisations which had fared well under the existing regime of regular inspections and had received positive assessments noted that the absence of inspection created a void, both in terms of reputation management and the sharing of best practice. In a context in which giving account of one's performance has become institutionalised, the lack of an audience for such accounts and a lack of opportunity to maintain or enhance reputations constituted a reputational threat.

\section{Past Selves: Protecting and Restructuring Reputation}

In their accounts of external performance assessments, respondents' discursive strategies differed in approach between historical assessments and the current performance framework. Interviewees made sense of historical judgements received through CPA and CAA by using alternate comparators and identities to excuse and justify rankings (Elsbach and Kramer 1996). On the one hand, respondents referred to the flawed methodology or 'check-list approach' (Chief Executive, Organisation D) of previous inspections. On the other hand, public managers used the 'organisation in transition' narrative to explain assessments which no longer conformed to their view of their organisation.

These strategies of sense-making were not valid in the context of the new external assessment paradigm as CPC did not provide easily quantifiable and comparable summary judgements which provided comparisons or clearly placed public service organisations in a hierarchy.

The CPA ultimately became about that league table and maintaining certain levels of activity from a political and senior officer point of view, I think. People's careers were both built and damaged by it accordingly. So there was a level of anxiety around CPA that rightly doesn't exist with the peer-led approach. (Corporate Director, Organisation E) 
Here the respondent justifies that findings from CPC do not require sense making as they do not threaten reputation in the same way as previous regimes. Instead it facilitates the management of reputation.

While this interviewee mentions both the advantages and disadvantages of a system characterized by league tables, others expressed concern about the lack of comparability in the new assessments. This requires them to work hard (discursively) to make sense of their engagement with $\mathrm{CPC}$. Respondents offered two rationales for participation in CPC: one of protecting both senior management's notions of the organisation's identity and its reputation through continued benchmarking, and another of an opportunity of identity and reputation restructuring. In the former instance, interviewees placed the emphasis on $\mathrm{CPC}$ as a 'reality check' (Council member, Organisation F) or as another instrument to assess performance by peers. In the latter strategy, CPC provided validation of a change in direction since the last assessment.

In both cases, respondents invoked the public organisation's current performance and their self-assessment. Here, they presented themselves as well-performing organisations that were keen to improve. As CPC was a relatively new mechanism at the time of interviewing, this also meant taking on pioneering roles in the sector for participating organisations.

There's probably a logic isn't there that if you're a reasonably well managed council and you're a council that really wishes to improve, then there's a fair chance that you're going to be the council that wants to continue to benchmark and performance manage. But if you're a council that's in dire political issues or you've got things that are going wrong, there might be a tendency to not wish to benchmark or to be measuring stuff anymore. (Middle Manager, Organisation B)

This quote is indicative of the majority of the respondents who not only identified themselves as self-cognizant performers keen to improve but also positioned themselves in opposition to those seen as 'coasting' (in CPA language), 'normal', or lacking dynamism and transparency. 
This reveals the interplay between organisational identity and reputation. Organisational identity is the filter through which a challenge is recognized and validated as a threat or as an opportunity for aspiration. Interviewees continued to use their organisational identity as a mechanism to justify the particular way in which CPC had been implemented. For instance, one interviewee highlighted that

if you're fairly good and excellent and you're breaking at the boundaries and want to think things differently, it's not local government we're going to learn from. Sorry. I don't mean to sound arrogant by that, but we want to learn more from other sectors. (Chief Executive, Organisation G)

Reputation, in contrast, "emerges as product of the way in which audiences respond to these attempts at self-presentation" (Busuioc and Lodge 2017, 93). The peer team in itself constituted an audience for the organisations giving accounts of their performance. Therefore, attempts to control the composition of these teams was an integral element of the reputational strategy. In the case above, the interviewee went on to suggest that the Peer Challenge team should involve peers from the private sector as well as the public sector. Similarly, other respondents highlighted their desire to include peers from organisations that were different to them to provide a sufficient level of challenge in a process that could otherwise be described as ‘stitched up' (Middle Manager, Organisation B) due to its flexibility.

In contrast to the literature on external performance assessment, interviewees did not work hard to justify the outcome of assessment but to make sense of the specific form of their engagement with the process. In their accounts, public managers were struggling with two related problems. The CPC programme reflects a move away from previously dominant principal-agent approaches in the practice of external performance assessment. As a result, public managers still felt the need to defend an involvement in a practice with the potential for reputational damage. In addition, in the new world of managing reputations, they wrestled with the 'uniqueness problem' (Wæraas and Byrkjeflot 2012) or the tensions arising out of 
seeking legitimacy and building reputation (Sataøen and Wæraas 2015). On the one hand, public managers wanted to be seen to conform to minimum standards of performance while, on the other hand, they wanted to engage in innovative practices (CPC) to improve their performative reputation and thus stand out.

\section{Future Selves: Reputational Aspirations}

While public managers used sensemaking techniques when talking about $\mathrm{CPC}$, it became clear that it had predominantly been employed - strategically - as a sensegiving practice within organisations and was shaped by internal agendas. Different groups within a council compete for resources and status (Carpenter and Krause 2012). External performance assessment delivered the necessary credibility to some groups over others. CPC provided a 'strengthened elbow' (Corporate Director, Organisation E), a response to internal resistance either by staff or local politicians. For example, peer reports which supported ideas of improvement, efficiency plans or change strategies, gave sense to suggested programmes by public managers. The scale of the budget reductions which local governments faced meant that most were forced to contemplate significant redundancies and cuts in service provision. Senior managers prized confirmation from peers that these changes were necessary and were in keeping with a forward-looking, innovative organisation. Typical of this group was a senior manager of a council whose performance had previously been rated as so 'poor' that it had been the subject of central government intervention. They reported that CPC played an important role in establishing a consensus among the politicians in support of the strategies that were being put forward by the senior management team:

Quite frankly we had some difficult stuff going on politically. And really, we didn't want that difficult political stuff to subvert the need for action [i.e. to improve the performance/service delivery]. And I think, what was interesting 
was that all parties accepted the recommendations of the peer challenge

$[\mathrm{CPC}]$ took the politics out of it to a degree. (Corporate Director, Organisation

H)

In particular, interviewees remarked on tensions between the administration and local politicians. In some cases, it was clear that the process was owned by senior corporate officers while in others, politicians "wanted a bit of feedback on their own relationships with the organisation and they wanted assurance that the organisation was fit for purpose for delivering what they wanted to achieve" (Middle Manager, Organisation I). Peers therefore played two important roles in the process. They could be presented as scapegoats for uncomfortable and contentious change programmes and also provide credibility to processes championed by local managers.

While these internal agendas were wide-ranging, the use of CPC in response can be categorised in two ways: under the labels of status extension or status reconfiguration (Kodeih and Greenwood 2014) to both internal and external audiences. Senior managers and politicians regarded CPC as a valuable means of bolstering internal and external legitimacy. Interviewees reported that they had engaged with CPC because they wished to shape the way that their organisation was viewed by their own staff and members (cf. Wæraas et al. 2015). In other words, senior management aimed to privilege one particular understanding of organisational identity (their own). Those organisations that had been labelled poor performers in the past used the new external performance assessment regime as a way of reconfiguring their status for both staff and external stakeholders highlighting 'structural change' in their accounts of themselves (cf. Kodeih and Greenwood 2014). In this way, CPC became a sense-giving practice, encouraging staff to focus on the future and the organisation's aspirations. 
Central government, other service providers in their locality (the police, health services and third sector organisations) and the local government sector as a whole were also important audiences.

A Peer Review to me has always got two elements to it I suppose and I think for any council it's a 50/50 internal/external message here, and when I say external, it's not just to your local community and your local media and your local politicians and your residents, but it is also with your peers. (middle manager, organisation B)

In this sense, $\mathrm{CPC}$ needs to be seen in the context of local government serving a range of constituents and thus participating in it (and receiving reasonably positive feedback) is about "conveying the impression of running a competent organization to much wider networks of audiences that might be only loosely connected" (Busuioc and Lodge 2016, 252). Organisations, which presented and saw themselves as having a long history of (recognized) high performance saw their involvement in CPC as a way of consolidating their position as a leading organisation in the local government sector. As local governments that were willing to learn from others and share the knowledge that they possessed, organisations gave accounts of being a good partner within the region and a responsible member of the wider sector. In some cases this was bound up with the Leader or the chief executive's desire to play a role in local government networks regionally and/or nationally. A senior manager reported:

'It's about ... how we play... a leading role within those groups rather than you know, just being an attendee or a participant and we seek to be much more engaged in those sorts of forums... we very much see ourselves part of that [local government] family now... and want to play a sort of leadership role within it'. (Senior manager, organisation I) 
External scrutiny by peers and subsequent development of partnerships confirmed positive performative reputation and paved the way for new roles within the sector.

In addition to the focus on extending status with peers in the local government sector, $\mathrm{CPC}$ was seen by many interviewees as an important means of influencing how they were regarded by other agencies in their locality. Building a reputation as a 'good partner' was important because of the increased emphasis in recent years on the need for local government to collaborate with health, police and other service providers to provide 'joined up services' and tackle 'wicked issues' which required coordinated action. Some interviewees reported that they used CPC to gauge whether they were living up to local partners' expectations but also as a re-affirmation of senior management views of the organisation and therefore the privileging of a specific organisational identity.

Whilst it is nice to get positive feedback from an external scrutiny group such as the LGA peer challenge, it is even nicer when you get a bit of endorsement from your day to day economic and community partners. [...] because whilst there are times we don't agree with each other or we won't be able to do what they want us to do at least they would say we... were a positive organisation to work with. [...] And I think we genuinely got a lot out of that in terms of our own self-awareness, our own morale. (Corporate Director, organisation C)

The emphasis on partnership working and the reputation as a good partner suggests that Carpenter and Krause's (2012) four dimensions could be extended to include 'collaborative reputation' as a reputational dimension of particular interest in the field of local government.

Many interviewees reported that CPC provided an important means of reassuring central government that their organisations could be trusted to manage their own affairs. The previous decade of intense top-down scrutiny of local government through CPA, CAA and other inspection regimes cast a long shadow. Many interviewees feared the re-imposition of mandatory external performance assessment unless the local government sector proved to be 
trustworthy and in any case, Ministers retained the power to intervene directly in the running of local governments that they judged to be failing. Interviewees spoke of their desire to promote a reputation as an organisation that was capable of self-regulating and taking responsibility for its own improvement. Examples of this narrative included the chief executive of a district council:

'If it [CPC] helps local government show to central government, primarily, that it is capable of taking care of its own improvement agenda, its own challenges, then yes, this is what it should be doing, it should tell central government what local government is capable of doing.' (Chief executive, Organisation J)

It is clear from our data that senior managers and politicians care deeply about how internal and external audiences make sense of their organisation. In an extension to the discussion of municipalities' organizational branding which privileged current and prospective staff as an audience (Wæraas et al. 2015, Bankins and Waterhouse 2019), we demonstrate that target audiences also include local and central government as well as other public sector partners. This is a consequence of the importance of the organisations' performative reputation. Performance is here seen as a central, enduring and distinctive characteristic as a result of previous assessments. Reputation management or organisational branding is not just about being a good service provider, good workplace and good employer (Wæraas et al. 2015: 1287, Bankins and Waterhouse 2019) but also and potentially more so about being a competent organisation. Here again, reputations made in the past frame the organisational response to the current regime. Engaging in external performance assessment becomes an essential tool for reputation management through status extension and reconfiguration (Kodeih and Greenwood 2014). In the extant literature, this is where the discussion ended. Our data, however, reveals respondents' awareness of their potential to impact on the future nature of threats. This is the focus of the following section. 


\section{Impact on Organisational Identity Threats: The future of external performance}

\section{$\underline{\text { assessment }}$}

The voluntary and evolving nature of CPC offered both advantages and disadvantages to public managers. While they regularly emphasized the positive aspects of being able to customize the process for their organisation's needs as it enabled them to manage the assessment as a sensegiving practice, there were also disadvantages associated with this malleability of the process. The following extract expresses this ambiguity:

So we've been working with the LGA to do this pilot process and we've sort of grown it up together and I think we've had some frustrations both ways on that. Number one, I expect their frustration is that we've been trying to influence what we want out of it which again is a little bit unusual. (...) And I've picked up there have been some concerns about whether we were stitching up the review by who was on the panel and it wasn't meant to be like that at all. (middle manager, organisation $\mathrm{B}$ )

While there were tensions around the ability of organisations to shape the assessment process, respondents also highlighted that it would only survive as a meaningful assessment, if a whole range of organisations engaged with it in an honest manner. Obvious 'stitching up' would result in a loss of credibility not only for the process but also those organisations associated with it. In this context, interviewees repeatedly mentioned the need to publish the peer challenge reports, whether the voluntary nature of the assessment should be reconsidered as well as ensuring that a procedure was in place to deal with potentially failing organisations if the assessment process brought such issues to light. In this sense, respondents described the relationship between external performance assessments and organisational responses as an interdependent and dynamic one. 
These discussions were, overwhelmingly, couched in terms of organisational identity which provided the filter for the recursive relationship between threats and responses. There were, however, different ways in which the resulting reputational profiles were seen to impact on the future of the assessment. Organisations that were considered weak or underperforming might play the system: "You can't expect that with whatever it is, four hundred authorities out there or something, that nobody will play games, because they will." (Chief Executive, Organisation K). Similarly, these organisations might create a perception of the process as one that only failing organisations use which would undermine both the organisations' strategic attempts at sensegiving and the sector's objective of independence. A chief executive of a previously poorly performing authority expressed his concerns:

Will people associate the peer review with ... an organisation [that] had a period of failure and therefore this is only something that failed councils need to have as opposed to something that is about learning? (Chief executive, organisation F)

These deliberations, however, reflect the previously dominant understanding of external performance assessments from a principal-agent perspective. In contrast, those organisations who saw themselves as high performers focused on the perception of the assessment as something that reflected CPC's potential for benchmarking and thus reputation management: "If you get approached by the Peer Challenge, if it becomes accepted which I am sure it can do, as the norm, then people will use it as a benchmark to judge one part of the sector against another." (corporate director, organisation C). In this way, CPC is less of a threat to organisational identity and more an opportunity to give account of one's performance to enhance reputation and strengthen senior management's organisational identity aspirations .

\section{Discussion}


This paper set out to examine the relationship between external performance assessments and reputation management. We used an approach which combined an analysis of sensemaking and sensegiving practices in accounts of organisational identity to demonstrate their interdependence (Gioia and Hamilton 2016). Our review of the literature highlighted three main issues. First, reputational threats are central to an understanding of organisational behaviour but the relationship between organisational identity and reputation has been underresearched. Second, the relationship between an organisation and its audiences in the reputational game requires more detailed examination (Carpenter 2010; Carpenter and Krause 2012; Maor, Gilad and Bloom 2015).Third, there is an underlying but unacknowledged tension in the literature on threats to organisational identity and reputation where they are seen as both filter for and outcome of organisational responses. As a result, our empirical, theoretical as well as practical contributions focus on the nature of the external performance assessments as organisational identity threats, the importance of audiences, and the dynamics between reputational threats to organisations and their responses. This carries implications for the acceptance and success of external performance assessment regimes.

\section{Threats and aspirations}

We started from a position where the extant literature on external performance assessment had highlighted how senior managers and politicians questioned the validity of centrally imposed performance assessments. At the same time, reputation was acknowledged as particularly important in the public sector given the multiple demands public organisations face:

This differentiation means that agencies are harder to characterize, which means (counterintuitively, but powerfully) that agency reputation is all the more important because organizational images offer forceful simplifications of more complicated agency realities, and 
they are often relied on more heavily when the agency is more complicated. (Carpenter and Krause 2012, 28)

It is therefore unsurprising that senior managers and politicians defined their organisations' identities in terms of the scoring systems used by previous external assessments and employed these to strengthen their own roles and strategies. In this sense, performance had become a central, enduring and distinctive element of organisational identity. Busuioc and Lodge $(2016,2017)$ describe this as the move from a principal-agent understanding to a reputational view of external performance assessment. We have demonstrated how this shift in theory and practice translates into a change in managers' strategies away from sensemaking towards using CPC as a sensegiving practice. Managers' support for CPC is evidence that the absence of performance assessment now constitutes an organisational identity threat and, in contrast, the assessment regime presents opportunities for identity aspirations and the management of performative reputation. CPC's perception as a strategic tool can be seen as a reflection of managers' sense of control in the process. In this sense, NPM has been successful in transforming bureaucratic organisations focused on service delivery into corporate entities striving for recognition as 'competent organisations' in their reputational profile. This also highlights the need for relevant audiences.

\section{Audiences}

While the multiplicity of audiences for public services has been acknowledged to lead to complex reputational profiles (Christensen and Gornitzka 2018), a focus on performative reputation, i.e. a competent organisation, service provider, employer and workplace (Wæraas Bjørnå and Moldenæs 2015, 1287; Bankins and Waterhouse 2019), was seen as predominantly geared towards internal audiences or prospective employees. Our analysis has shown that external audiences are equally as important in the pursuit of a reputation as 'competent organisation'. We show that performative reputation is a key ingredient in 
resolving resource and political struggles between competing groups within organisations. In terms of external audiences, the local government sector, public and private partners as well as central government are all seen as relevant because performative reputation can have an impact on the public organisation's capacity to act. Positive performative reputations enable autonomy (Carpenter and Krause 2012). We argue that collaborative reputation is another important reputational dimension, especially in the context of local government, as this provides a platform for the creation and maintenance of relationships in the sector. In particular, we propose that collaborative reputation is significant for organisation-specific audiences (e.g. local partners/ competitors) compared to the wider, general, network of audiences. This supports the notion that different elements of the reputational profile are relevant to different audiences (Christensen and Gornitzka 2018). Thus, we also suggest a lower salience of the reputation of local government organisations as good corporate performers to the public compared to their moral reputation, for instance. At the same time, the acceptance of reputational profiles addresses concerns about the 'uniqueness' problem in public sector branding. Wæraas and Byrkjeflot (2012: 198) argue that public organisations may find themselves in a 'conformity trap'. External performance assessment can provide strong performative reputation through similarity (meeting the minimum standards of the local government 'family') while at the same time providing strong performative reputation through uniqueness by highlighting organisations' innovative ways of achieving excellence.

\section{Dynamics}

We followed the argument that "an organisation's image and identity guide and activate individuals' interpretations of an issue and motivations for action on it, and those interpretations and motivations affect patterns of organisational action over time" (Dutton and Dukerich, 1991: 517). Similarly, Maor et al (2015) argue that an organisation's assessment of reputational threat shapes their response. Here the distinction between 
organisational identity and reputation is of importance. Organisational identity is a filter for making sense of organisations' behaviour. It shapes the construction or assessment of the reputational threat, the organisation's response to it and the potential impact on the reputational threat itself. Reputation can be the outcome of these processes and exert an influence over the maintenance or privileging of specific organisational identities.

External performance assessments established as part of NPM provoked organisational responses whose impact, however, was undermined through a rapid change in the assessment regimes. Reputations made through one regime, through their impact on organisations' view of themselves, dictated responses to the next regime and in turn had an impact on the viability and credibility of the external performance assessment. In contrast to CPA and CAA, the impact of engaging with $\mathrm{CPC}$ was not limited to individual organisations but the local government sector as a whole. Organisations which presented themselves as 'excellent' performers saw CPC as a sensegiving practice not only to their local internal and external stakeholders but also saw their participation as a way of giving sense to the new, voluntary, customized external peer challenge. They gained credibility through external assessment and the assessment gained credibility through them. The relationship between identity, reputation and external performance assessment is thus a dynamic and reciprocal one.

This study provides empirical support to extant discussion of relationships between organisations giving account of themselves and their account holders. In previous work, the case we present here, where both local government and its sector representative organisation have a high reputational investment and strong interest in external performance assessment, would be characterised as a scenario of "intense heat" (Busuioc and Lodge 2017: 97). In this situation, the authors expect public organisations to emphasise their successes, downplay areas of underperformance and engage in gaming. Emerging out of our study of voluntary 
external performance assessment in local government, we find diverging patterns to these expectations. While there were calls for comparability, interviewees did not engage in elaborate blame games. In our study, it becomes clear that public service organisations (account givers) and their sector representative organisation (account holder) are in a horizontal relationship with each other. In contrast, their relationship with their principal, i.e. central government, remains hierarchical and colours their approach to external performance assessment. This means they both have an interest in minimising gaming but also maximising collaboration. It also means that principal-agent theories may retain some applicability in this area.

In summary, our study highlights the importance of conceptualising external performance assessments as dynamic, reciprocal processes which have strategic importance for senior management rather than discreet events threatening organisational identity and reputation. Relations within audience networks deserve particular attention to make sense of organisations' approaches to reputation management. On the one hand, hierarchical relations may continue between audiences. On the other hand, reputational strategies may differ depending on whether the groups targeted are organisation-specific (employees, partners, competitors) or general (the sector as a whole, central government). We also suggest 'collaborative reputation' as an additional dimension of reputational profiles in the context of local government.

From a practical perspective this means that public managers strategically engage with external performance assessment which they perceive as meaningful for their own organisations but also for the sector as a whole. Providers of such assessments need to consider this interdependence when designing these programmes and to be open to responding to public managers' feedback. They may be able to increase participation in such programmes by communicating the potential win-win situation for organisations and the 
sector: organisations can demonstrate meeting minimum standards but also showcase excellence which strengthens the credibility of both participating organisations and the external performance assessment mechanism.

\section{Acknowledgements}

We would like to thank the editor and the two anonymous reviewers for their constructive and supportive comments on earlier versions of this article. Thanks are also due to Rachel Ashworth, Tim Edwards, Tom Entwistle and Mike Reed for their advice in the development of this article.

\section{References}

Albert, S. and D. A. Whetten. 1985. 'Organisational identity'. Research in organisational behavior 7: 263-295.

Ashworth, R., G. A. Boyne and R. M. Walker. 2002. 'Regulatory problems in the public sector: theories and cases'. Policy \& Politics 30: 195-211.

Bankins, S. and J. Waterhouse, 2019. Organizational Identity, Image and Reputation: Examining the Influence on Perceptions of Employer Attractiveness in Public Sector Organizations, International Journal of Public Administration, 42(3), 218 - 229. DOI: 10.1080/01900692.2018.1423572.

Bjørnå, H. 2015. 'Dealing with Stakeholders in Local Government: Three Norwegian Cases of Municipal Reputation Management' in Wæraas, A. and M. Maor (eds), 2015. Organizational Reputation in the Public Sector. Routledge: New York and London, 185 202. 
Boyne, G. A. 2003. 'What is Public Service Improvement?' Public Administration 81: 211228.

Busuioc, E. M. and M. Lodge, 2016. The Reputational Basis of Public Accountability, Governance, 29(2), $247-263$.

Busuioc, M. and M. Lodge, 2017. Reputation and Accountability Relationships: Managing Accountability Expectations through Reputation, Public Administration Review, 77(1), 91 100.

Carpenter, D., 2010. Institutional strangulation: Bureaucratic politics and financial reform in the Obama administration. Perspectives on Politics, 8(3), 825-846.

Carpenter, D.P. and Krause, G.A., 2012. Reputation and public administration. Public administration review, 72(1), 26-32.

Christensen, T. and Å. Gornitzka, 2018. Reputation Management in Public Agencies: The Relevance of Time, Sector, Audience and Tasks, Administration and Society, Advance online publication. doi:10.1177/0095399718771387.

Dutton, J. E. and J. M. Dukerich, 1991. 'Keeping an eye on the mirror: Image and identity in organisational adaptation'. Academy of Management Journal 34 (3): 517-554.

Elsbach, K. D. and R. M. Kramer. 1996. 'Members' responses to organisational identity threats: encountering and countering the Business Week rankings', Administrative Science Quarterly 41: 442-476.

Gilad, S., 2015. Political Pressures, Organizational Identity and Attention to Tasks: Illustrations from Pre-Crisis Financial Regulation, Public Administration, 93(3), 593 - 608. 
Gioia, D. A., K. Price, A. L. Hamilton, and J. B. Thomas. 2010. 'Forging an identity: An insider-outsider study of processes involved in the formation of organisational identity'. Administrative Science Quarterly 55: 1-46.

Gioia, D. A. and A. L. Hamilton. 2016. 'Great Debates in Organisational Identity Study' In The Oxford Handbook of Organisational Identity, edited by M. G. Pratt, M. Schultz, B. E. Ashforth and D. Ravasi. Oxford University Press, 21- 38.

Hatch, M. J. and M. Schultz. 2002. 'The dynamics of organisational identity'. Human Relations 55: 989-1018.

Houlberg Salomonsen, H. and J.A. Nielsen, 2015. 'Investigating the Politics of Reputation Managenment in Local Government: The Case of Denmark' in Wæraas, A. and M. Maor (eds), 2015. Organizational Reputation in the Public Sector. Routledge: New York and London, $203-226$.

Jacobs, G., J. Christe-Zeyse., A. Keegan, and L. Pólos, L. 2008. 'Reactions to organisational identity threats in times of change: Illustrations from the German police'. Corporate Reputation Review 11 (3): 245-261.

Karsten, N., 2015. Scrutinize me, please! The drivers, manifestations and implications of accountability-seeking behaviour. Public Administration, 93(3): 684-699.

Kodeih, F. and R. Greenwood 2014. 'Responding to Institutional Complexity: The Role of Identity'. Organisation Studies 35 (1): 7-39.

LGA (Local Government Association) 2016. The LGA's corporate peer challenge offer. London: LGA.

Maor, M., 2015. Theorizing bureaucratic reputation. In Organizational reputation in the public sector, edited by A. Wæraas and M. Maor. Routledge, 17 - 36. 
Maor, M., Gilad, S. and Bloom, P.B.N., 2012. Organizational reputation, regulatory talk, and strategic silence. Journal of Public Administration Research and Theory, 23(3), 581-608.

Martins, L. L. 2005. 'A model of the effects of reputational rankings on organisational change'. Organisation Science 16 (6): 701-720.

Meyer, R. and Hammerschmid, G. 2006. 'Public Management Reform: An Identity Project'. Public Policy and Administration 21 (2): 99-115.

Osborne, S. P. 2017. 'Public management research over the decades: what are we writing about?' Public Management Review 19 (2): 109-113.

Palma, P. J., M. P. E. Cunha, and M. P. Lopes. 2010. 'The best of two worlds: How privatization affects the identity of a public organisation'. Public Management Review 12 (5): 725-746.

Power, M. 2007. The Audit Society. Rituals of Verification. Oxford: Oxford University Press.

Radin, B. 2006. Challenging the Performance Movement: Accountability, Complexity, and Democratic Values. Washington DC: Georgetown University Press.

Randel, A.E., Jaussi, K.S. and Standifird, S.S., 2009. Organizational responses to negative evaluation by external stakeholders: The role of organizational identity characteristics in organizational response formulation. Business \& Society, 48(4): 438-466.

Ratner, H. 2012. 'It was the night of the long knives' when public management collides with group identities'. Public Management Review 14 (1): 23-40.

Ravasi, D. and A. Canato. 2013. 'How Do I Know Who You Think You Are? A Review of Research Methods on Organisational Identity'. International Journal of Management Reviews 15: $185-204$. 
Ravasi, D. and M. Schultz. 2006. 'Responding to Organisational Identity Threats: Exploring the Role of Organisational Culture'. Academy of Management Journal 49 (3): 433-458.

Rondeaux, G. 2006. 'Modernizing public administration: the impact on organisational identities'. International Journal of Public Sector Management 19: 569-584.

Rondeaux, G. 2014. 'What are the dynamics of organisational identification in the course of modernization processes: Analysis of a Belgian administration'. International Review of Administrative Sciences 80 (1): 110-130.

Sataøen, H.L. and Wæraas, A., 2015. Branding without unique brands: Managing similarity and difference in a public sector context. Public Management Review, 17(3), 443-461.

Seeber, M., B. Lepori, M. Montauti, J. Enders, H. De Boer, E. Weyer, I. Bleiklie, K. et al. 2015. 'European universities as complete organisations? Understanding identity, hierarchy and rationality in public organisations'. Public Management Review 17 (10): 1444-1474.

Skålen, P. 2004. New Public Management Reform and the Construction of Organisational Identities, International Journal of Public Sector Management, 17 (3): 251-263.

Tonkiss, K. and C. Skelcher. 2015. 'Abolishing the Audit Commission: Framing, Discourse Coalitions and Administrative Reform'. Local Government Studies 41 (6): 861-880.

Tuck, P. 2015. 'The dynamics of 'virtuous organisational identity: the case of regulating or enabling corporate tax compliance'. Accounting, Finance and Governance Review 2: 25-41.

Wæraas, A. 2010. 'Communicating Identity: The Issue of Core Value Statements in Regulative Institutions'. Administration and Society 42 (5): 526-549.

Wæraas, A., Bjørnå, H. and Moldenæs, T., 2015. Place, organization, democracy: Three strategies for municipal branding. Public Management Review, 17(9), 1282-1304. 
Wæraas, A. and Byrkjeflot, H., 2012. Public sector organizations and reputation

management: Five problems. International Public Management Journal, 15(2), 186-206.

Wæraas, A. and M. Maor (eds), 2015. Organizational Reputation in the Public Sector.

Routledge: New York and London.

Wæraas, A. and Sataøen, H.L., 2015. Being all things to all customers: Building reputation in an institutionalized field. British Journal of Management, 26(2), 310-326.

Wynen, J. and K. Verhoest. 2015. 'Do NPM-type reforms lead to a cultural revolution within public sector organisations?' Public Management Review 17 (3): 356-379.

\footnotetext{
' Local government organisations in the UK differ in the size and nature of the area they cover and the responsibilities they carry out. The different forms of organisations are: district councils, county councils, unitary councils (combining district and county responsibilities), borough councils (traditionally covering urban areas).
} 